\title{
Die invloed van seisoene en streeksverskille op die samestelling van koeimelk in die RSA
}

\author{
J.A. Bester, L.E. Smit*, D.J. de Lange en L. van Rensburg \\ LNR-Dierevoeding en Produkte Instituut, Privaat sak X2, Irenc, 0062 \\ M.F. Smith \\ Departement Statistiek, Universiteit van Suid-Afrika, Posbus 392, Pretoria, 0001 \\ W.H.J. de Beer \\ Technikon Pretoria, Departement Chemic en Fisika, Posbus 56208, Arcadia, 0007
}

Onnamg 7 Januarie 1997; ananvar $3 /$ Julie 1997

\section{UITTREKSEL}

Die invloed van seisoene en strecksverskille op die voedingsinhoud en samestelling van melk is sistematies ondersoek. Die statistiese tegniek van kanoniese veranderlike analise (KVA) is anngewend om die verskille tussen die verskeie veranderlikes in die onderskeie streke binne die Republiek van Suid-Afrika tydens die somer-en wintermande aan te dui.

Slentelwoorde: kanoniese veranderlike analise, melk, voedingsinhoud, seisoen, streke

\section{Anstract}

The seasonal and regional influence on the composition of cows' milk in the Republic of South Africa Canonical variate analysis was used to attain a better understanding of seasonal and regional factors which could contribute to variation in the milk nutrient content of milk in the RSA.

Keywords: canonical variate analysis, milk, nutrient content and composition, seasons, regions

\section{INLEIDING}

Melk is seker een van die belangrikste voedingstowwe vir die mens en is die enigste voedsel wat soogdiere, insluitende die mens, tydens die cerste gedeclte van sy bestaan inneem. Melk bevat voldoende konsentrasies minerale, proteïene en vitamiene in dic korrekte verhouding vir optimale absorpsic wat enige suigeling nodig het om tc ontwikkel.' Reeds op 'n jong ouderdom word moedersmelk aangevul met kocimelk en melkprodukte. Heclwat navorsing is dic afgelope jare, veral in die buiteland gedoen om die voedingswaarde van kocimelk en melkprodukte te bepaal en die voedingswaarde wat dit veral vir swanger vroue, kinders en bejaardes inhou, is al goed gedokumenteer. ${ }^{1.2}$ Dit is bekend dat die samestelling van melk by verskillende becsrasse verskil $\mathrm{en}$ inligting oor die scisoenale en strecksinvloed op die samestelling van melk is beskikbaar.
Baic kinders in agtergeblewe gemeenskappe in die RSA, veral in plattelandse gebiede, is ondervoed en die regering is tans besig met dic beplanning van ' $\mathrm{n}$ voedsclaanvullingsprojek om hierdic agterstand te probeer uitwis. Werkswinkels word tans gehou om ' $n$ geskikte medium vir die aanvulling van veral vitamiene $A$, yster en foliensuur te vind. Hicrdie studic is gedecltelik geloods om te bepaal of melk landswyd in voedingswaarde verskil.

Melk en melkprodukte atkomstig van verskeic produsente is op verskillende tye van die jaar in verskillende supermarkte in vyf streke in dic RSA aangekoop en geanaliscer. Resultate vanuit die analises gegenereer, is strecks en seisoenalal met mekaar vergelyk deur van dic KVA-tegnick gebruik te maak. ${ }^{3}$ Dic gemiddelde samestellingwaardes van volroommelk (VRM), laevetmelk (LVM) en ultrahoètemperaluurmelk (UHTM) in die onderskeic streke van die RSA, tydens die somer- en wintermaande (tabel 1), is ondersock.

TABEL 1 Die gemiddelde samestelling van sekere komponente vir VRM, LVM en UHTM, soos bepaal tydens somer en winter, in sekere streke van die RSA

\begin{tabular}{|c|c|c|c|c|c|c|c|}
\hline \multirow{2}{*}{\multicolumn{2}{|c|}{ Melkkomponente }} & \multicolumn{2}{|c|}{ VRM } & \multicolumn{2}{|c|}{ LVM } & \multicolumn{2}{|c|}{ UHTM } \\
\hline & & \multirow{2}{*}{$\begin{array}{c}\text { somer } \\
46,81\end{array}$} & \multirow{2}{*}{$\begin{array}{c}\text { winter } \\
49,87\end{array}$} & \multirow{2}{*}{$\begin{array}{c}\text { somer } \\
43,66\end{array}$} & \multirow{2}{*}{$\begin{array}{c}\text { winter } \\
49,30\end{array}$} & \multirow{2}{*}{$\begin{array}{c}\text { somer } \\
48,31\end{array}$} & \multirow{2}{*}{$\begin{array}{c}\text { winter } \\
49,82\end{array}$} \\
\hline natrium & $(\mathrm{mg} / 100 \mathrm{~g})$ & & & & & & \\
\hline kalium & $(\mathrm{mg} / 100 \mathrm{~g})$ & 160,93 & 153,63 & 145,91 & 158,59 & 138,75 & 156,07 \\
\hline C14:1 & $(\mathrm{mg} / 100 \mathrm{~g})$ & 22,33 & 25,75 & 20,65 & 15,26 & 28,41 & 25,03 \\
\hline C16:0 & $(\mathrm{mg} / 100 \mathrm{~g})$ & 778,68 & 828,41 & 596,30 & 472,13 & 712,18 & 876,21 \\
\hline C18:1 & $(\mathrm{mg} / 100 \mathrm{~g})$ & 760,09 & 808,89 & 595,07 & 492,79 & 724,03 & 933,66 \\
\hline cholesterol & $(\mathrm{mg} / 100 \mathrm{~g})$ & 10,98 & 8,28 & 6,97 & 7,46 & 7,87 & 11,81 \\
\hline energie & $(\mathrm{kJ} / 100 \mathrm{ml})$ & 290,38 & 295,92 & 234,95 & 231,10 & 274,84 & 282,26 \\
\hline vitamien $B_{1}$ & $(\mathrm{mg} / 100 \mathrm{ml})$ & 20,63 & 22,46 & 21,38 & 19,71 & 19,38 & 20,62 \\
\hline vitamien $\mathrm{B}_{2}$ & $(\mathrm{mg} / 100 \mathrm{ml})$ & 176,71 & 140,00 & 182,57 & 139,40 & 147,93 & 136,69 \\
\hline$\alpha$-tokoferol & $(\mu \mathrm{g} / 100 \mathrm{ml})$ & 107,42 & 106,73 & 89,62 & 59,64 & - & 143,33 \\
\hline
\end{tabular}

\footnotetext{
* Outeur aan wie korrespondensie gerig kan word.
} 


\section{EKSPERIMEN'TEEI}

\section{Eksperimentele ontwerp}

Twintig monsters elk van die drie melkprodukle wal bespreck word, is in supermakte in stede in Gauteng, dic Vrystat, KwalZulu-Natal, Wes-Kalap en Oos-Kaap versamel. Die slede wall vir die doel gekies is, is Pretoria, Bloemfonlein, Durban, Kalapstad en Port Elizabeth. Om die monsterneming so verteenwoordigend moontlik te maak, is produkte van die bekendste verspreiders van verskillende supermarkte alangekoop. Gelyke hoeveelhede produkte van onder andere die volgende produsente: Clover, Melba, Dairylselle, Creamline, Towerkop en Bomita is van die supermarkte: Pick \& Pay, Checkers, OK, Hyperama, Shoprite Checkers en SPAR alangekoop. Deur op die vervaldatums van die onderskeic produkte te let, is deurgalns probeer om vars produkte aan te koop. Die produkte is in koclhouers op ys verpak en na die LNR-Dierevoeding en Produkte Instituut te Irene vervoer waar dit tot $40^{\circ} \mathrm{C}$ in ' $n$ waterbad verhit is voordat dit vir ontleding homogeen vermeng en verdecl is.

\section{Analitiese tegnieke en geanalisecrde komponente}

Verskeic analitiese legnicke is angewend om die sowat 54 melkkomponente kwantitatief te hepaal. Die Kjeldahl-metode is gebruik vir die bepaling van proteiene, nic-kaseienstikst of (NKN) en nic-proteienstikstof (NPN). Vet is met hehulp van die Majonnier-metode bepalal, terwyl vog, tolale vaste stowwe en asinhoud gravimetries bepalal is. Mincrale $\left(\mathrm{Cl}, \mathrm{P}, \mathrm{PO}_{4}{ }^{3}, \mathrm{Na}^{+}, \mathrm{K}^{+}\right.$, $\mathrm{Mg}^{2+}$ en $\left.\mathrm{Ca}^{2+}\right)$ is deur middel van ioonchromatografie bepaal. Dic vetsure: kapriensuur (Cl0:(0), lauriensuur (C12:()), miritiensuur (C/4:()), miristoliensuur (Cl4:1), palmiliconsuur (C/6), palmitoolsuur (C16:I), stcaricnsuur (Cl8:(0), olcïensuur (CI8:1), linoleïensuur (C18:2), linolecnsuur (C18:3) en aragiensuur (C20:0) is deur middel van gaschromalogralie bepalal.

Iloëverrigtingvlocistofchromatografie (IIVVC) is aangewend vir die bepaling van laktose, vit. $\mathrm{B}_{1}$, vit. $\mathrm{B}_{2}$, vit. $\mathrm{B}_{6}$, retinol, $\mathrm{B}$ karoten, retinol ckwivalent en $\infty$-tokoferol. Energiewaardes is met 'n bomkaloriemeter bepaal, terwyl gaschromatografie aangewend is vir die bepaling van cholesterol. IIVVC is gebruik vir die bepaling van die aminosure: arginien, serien, asparagiensuur, glutamicnsuur, treonien, glisien, alanien, tirosien, prolicn, metionien, valien, feniclalanien, isoleusien, leusien, histidien, lisien, triptofaan en sistien.

\section{Statistiese tegniek}

Die statistiese tegniek van kanoniese veranderlike analise (KVA), ook bekend as liniêre diskriminante analise, is angewend. ${ }^{3}$ Die tegniek word gebruik wanneer die verskille lussen spesifieke groepe belangriker is as byvoorbecld dic verskil tussen individue. Aanvanklik word die variasie van die volledige stel veranderlikes verminder na 'n kleiner stel veranderlikes wat vir die grootste gedecle van die variasie verantwoordelik is. llierdie nuwe stel veranderlikes is ctus liniêre kombinasies, dus ook ladingsveklore van die oorspronklike stel waardes en staan bekend as die kanoniese veranderlikes. Deur hierdie benadering word 'n groep vektore verkry waarvan die verhouding van lussengroepveranderlikheid tot binnegroepveranderlikheid in elke rigling geoptimeer word. Die veranderlikes in hierdie geval was die 54 karakteristicke melkkomponente.

Deur die walardes van elke kanoniese veranderlike te korreleer met die waardes van die oorspronklike veranderlikes, is dit moontlik om 'n stel veranderlikes te identifiseer met die grootste diskriminasie tussen die helrokke groepe. In die geval vall die melkprodukte wat vir hierdie studie gekies is, mamlik VRM, LVM en UI'TM is daar dus 10 groepe salamgestel uit die vyf verskillende streke plus die (wee seisoenale veranderings (winter en somer) in dié streke. Die aansienlike variasie tussen die walardes van die groepe is gestabiliseer deur logaritmes van die veranderlikes te neem.

\section{RESUITATE}

Die gemiddelde winter- en somerwalardes van die verskillende komponente waaruit VRM, LVM en UHTM in die RSA salamgestel is, verskyn in tabel 1 . Om 'n beter begrip te verkry van hoe die verskillende groepe van inckanr verskil en te bepalal wat die prominentste diskriminerende veranderlike is, verskyn die kanoniese waardes in tabel 2. Die eerste en tweede kanoniese veranderlikes (KV 1 en KV2) verteenwoordig onderskeidelik die seisoenale en streckswalardes en hul grocperings.

\section{Volroommelk (VRM)}

Volgens label 2 is die eerste twee kanoniese veranderlikes $\mathrm{KVI}$ en KV2 vir $57 \%$ van die lotale variasie tussen groepe verantwoordelik. Dit is opvallend dat die walardes van KVI negatiel in

TABEL 2 Die persentasievariasie van die kanoniese veranderlikes en die gemiddelde waardes van die eerste kanoniese veranderlikes van drie melktipes, naamlik VRM, LVM en UHTM tydens somer (s) en winter (w)

\begin{tabular}{|l|c|c|c|c|c|c|}
\hline \multirow{2}{*}{ Groep } & \multicolumn{2}{|c|}{ VRM } & \multicolumn{2}{c|}{ LVM } & \multicolumn{2}{c|}{ UHTM } \\
\cline { 2 - 7 } & KV1 & KV2 & KV1 & KV2 & \multicolumn{2}{c|}{ KV1 } \\
\hline \multirow{2}{*}{$\%$} & 37,6 & 19,4 & 29,1 & 19,2 & 64,9 & 13,5 \\
SP & $-0,55$ & 2,52 & $-4,41$ & 10,74 & $-2,14$ & $-6,39$ \\
sB & $-5,48$ & 1,11 & $-9,87$ & $-1,52$ & $-24,44$ & 3,59 \\
sD & $-8,62$ & $-1,39$ & $-6,16$ & 2,37 & 0,23 & $-10,91$ \\
sK & $-5,20$ & 3,63 & $-11,67$ & $-8,63$ & $-3,84$ & $-5,84$ \\
sPE & $-7,92$ & $-0,41$ & $-1,88$ & 0,23 & $-18,95$ & 3,06 \\
WP & 6,61 & 9,26 & 5,90 & $-2,08$ & 6,80 & 4,25 \\
WB & 7,86 & $-2,14$ & 2,58 & $-6,90$ & 7,54 & 2,42 \\
WD & 4,71 & 0,63 & 4,78 & $-4,43$ & 6,56 & 2,63 \\
WK & 5,71 & $-3,50$ & 5,45 & 2,02 & 7,09 & 3,25 \\
wPE & 2,29 & $-7,76$ & 7,06 & 4,51 & 7,95 & $-0,01$ \\
\hline
\end{tabular}


die somer en positief in die winter is. Dus onderskei dic eerste kanoniese veranderlike tussen seisoene. Hierdie verskynsel word duidelik deur figuur 1 geillustreer waar al die somerwaardes links van die $y$-as (nulpunt) in 'n byna horisontale rigting gegroepeer is. Tabel 3 toon die melkkomponente wat die meeste tussen die seisoene diskrimineer, die betrokke korrelasiekoëffisiënte sowel as die relevante gemiddelde. Die mees diskriminerende melkkomponente in hierdie geval is vitamien $B_{2}(r=-0,76)$ en cholesterol $(r=-0,57)$. Dit is opvallend dat die waardes vir vitamien $B_{2}$ en cholesterol bogemiddeld vir die somerperiode is, terwyl dit ondergemiddeld vir die winterperiode is. Figuur I dui 'n duidelike onderskeid aan tussen dic somerwaardes van Durban (sD) en Port Elizabeth (sPE) en dic winterwaardes van Kaapstad (wK), Bloemfontein (wB) en Port Elizabeth (wPE) as een groep op die negatiewe kant van die KV2-as, teenoor die somerwaardes van Pretoria (sP), Bloemfontein (sB), Kaapstad $(\mathrm{sK})$ en die wintermaande van Pretoria $(w P)$ en Durban ( $w D)$ as 'n volgende groep aan die positiewe kant van die KV2-as. Wanneer die KVA- tegniek gebruik word, moet in gedagte gehou word dat, hoe nader die punte in die ligure aan mekaar lê, hoe groter is die ooreenstemming tussen die groepe wat met mekaar vergelyk word, die Durban (sD)- en Port Elizabeth (sPE)-somergroepe, terwyl groter afstande tussen die punte, groter verskille tussen die diskriminerende veranderlikes aandui. Volgens figuur 1 is daar dus groot verskille in die wintermaande tussen VRM wat onderskeidelik in Port Elizabeth $(-7,76)$ en in Pretoria $(9,26)$ gekoop word. Die melkkomponente wat in hierdie geval vir die meeste diskriminasie verantwoordelik is, is alfa-tokoferol, in welke geval die verskille tussen die stede se waardes groter as die verskille lussen seisoene is. Die punte vir die winterwaardes is meer verspreid as die van die somerwaardes (figuur 1).

\section{Laevetmelk (LVM)}

Die eerste twee kanoniese veranderlike gemiddelde (KVG) met hul betrokke persentasies word in tabel 2 aangedui en verteenwoordig $48,3 \%$ van die totale variasie tussen die groepe. Soortgelyk aan die geval van VRM toon LVM ook'n negatiewe KVl-waarde in die somer, terwyl positiewe KVl-waardes in die wintermaande verkry word. Somer en winter word dus weer met mekaar gekontrasteer. Die melksamestellingskomponente wat in hierdie geval tussen die seisoene diskrimineer, word in tabel 4 aangetoon.

Vitamien $B_{2}$ kom, soos in die geval van VRM, weer voor terwyl natrium en kalium ook voorkom. Die gemiddelde waarde vir vitamien $\mathrm{B}_{2}$ is weer bogemiddeld in die somer, terwyl ondergemiddelde waardes vir bogenoemde minerale tydens die winterperiode verkry is. Die gemiddelde waardes vir die somerperiode vir Pretoria (sP), Durban (sD) en Port Elizabeth

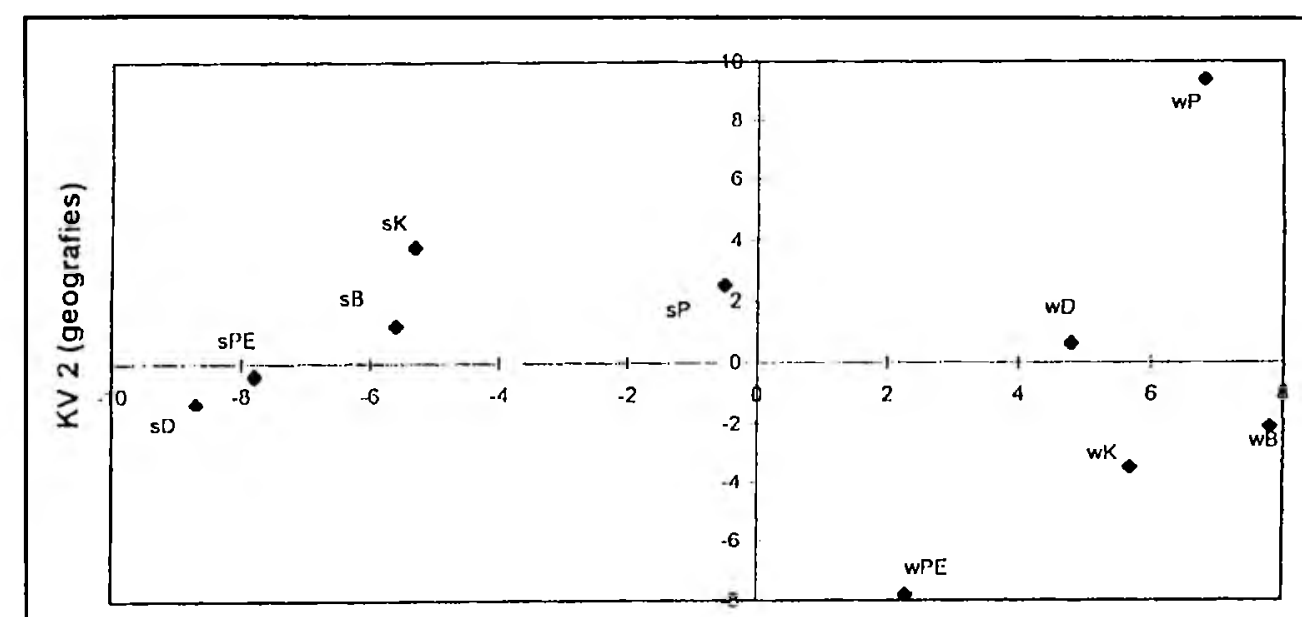

KV 1 (seisoenaal)

FIGUUR I: Kanoniese veranderlike gemiddeldes vir die eerste twee kanoniese veranderlikes van VRM.

TABEL 3 Die gemiddelde waardes van die belangrikste diskriminerende melkkomponente en die korrelasiekoëffisiënte vir VRM

\begin{tabular}{|c|c|c|c|c|c|c|c|}
\hline \multicolumn{3}{|c|}{ KV1 } & \multicolumn{5}{c|}{ KV2 } \\
\hline $\begin{array}{c}\text { Melk- } \\
\text { komponent }\end{array}$ & $\mathrm{r}$ & $\begin{array}{c}\text { Winter- } \\
\text { gemiddeld }\end{array}$ & $\begin{array}{c}\text { Somer- } \\
\text { gemiddeld }\end{array}$ & \multicolumn{4}{|c|}{ Wintergemiddeld } \\
\cline { 5 - 8 } & & & Melkkomponent & $r$ & Pretoria & Port Elizabeth \\
\hline vitamien $\mathrm{B}_{2}$ & $-0,76$ & 140,0 & $\mathbf{1 7 6 , 7 1}$ & alfa-tokoferol & $-0,60$ & 69,0 & 156,5 \\
cholesterol & $-0,57$ & $\mathbf{8 , 2 8}$ & 10,98 & & & & \\
\hline
\end{tabular}

TABEL 4 Die gemiddelde waardes van die belangrikste diskriminerende melkkomponente en die korrelasiekoëffisiënte vir LVM

\begin{tabular}{|l|c|c|c|l|c|c|c|}
\hline \multicolumn{3}{|c|}{ KV1 } & \multicolumn{5}{|c|}{ KV2 } \\
\hline $\begin{array}{l}\text { Melk- } \\
\text { komponent }\end{array}$ & $r$ & $\begin{array}{c}\text { Winter- } \\
\text { gemiddeld }\end{array}$ & \multirow{2}{*}{$\begin{array}{c}\text { Somer- } \\
\text { gemiddeld }\end{array}$} & & \multicolumn{4}{|c|}{ Somergemiddeld } \\
\cline { 5 - 8 } & & & Melkkomponent & $r$ & Pretoria & Kaapstad \\
\hline vitamien $B_{2}$ & $-0,63$ & 139,7 & 182,6 & vitamien $B_{1}$ & 0,73 & 30,89 & 18,86 \\
natrium & 0,63 & 49,30 & 43,66 & cholesterol & 0,85 & 10,98 & 8,28 \\
kalium & 0,72 & 158,6 & 145,9 & & & & \\
\hline
\end{tabular}


(sPE) en die winterperiode van Kaapstad (wK) en Port Elizabeth (wPE) word deur KV2 gekontrasteer met die winters van Pretoria (wP), Bloemfontein ( $w B$ ) en Durban (wD) en dic somers van Kaapstad (sK) en Bloemfontein (sB). Dit is opvallend dat die kanoniese waardes vir die somermainde baic meer verspreid lê (op die KV2-as) as die winterwalrdes. Die somerwalarde vir Pretoria (sP) is byvoorbeeld 10,74 terwyl Kaapstad se waarde tydens diesellde periode $-8,63$ is. Die melksamestellingskomponente wat in hierdie geval (KV2) die meeste diskrimineer, is vitamien $B_{1}$ en cholesterol wat beide ondergemiddeld vir Kaapstad en bogemiddeld vir Pretoria is.

\section{Ultrahoütemperatuurmelk (UHTM)}

Die mees diskriminerende melksamestellingskomponente, korrelasiekoëflisiënte en gemiddelde waardes vir UH'TM verskyn in tabel 5 .

Uit tabel 2 is dit duidelik dat die eerste twee veranderlikes $78,4 \%$ van die totale variasie tussen die groepe verteenwoordig. Die KVI-waardes vir die somermaande is, soos in die geval van VRM en LVM, weer negatief (KVI-as) vir die meeste stede en kontrasteer KVI weer duidelik somer en winter. Die UIITMwaardes verskil egter van die VRM en LVM daarin dat die KVI groepering drie duidelik onderskeibare groepe toon (liguur 3). Dic somerwaardes van Bloemfontein (sB) en Port Elizabeth (sPE) toon groot negatiewe KVI-walardes wat hulle onderskei van die kleiner negatiewe waardes van Kaapstad (sK) en Pretoria (sP) met 'n klein positiewe waarde vir Durban (SD). Hierteenoor toon alle wintermonsters positiewe KV-waardes wat nie baic van mekaar verskil nic. Anders as by VRM en LVM diskrimineer palmitiensuur, oleiensuur en miristoliensuur tussen die groepe. Die ander melksamestellingskomponente wat ook diskrimineer, is cholesterol en in ' $n$ mindere mate kalium. Die korrelasickoëffïsiënte vir palmitiensuur, oleiensuur en cholesterol is positief terwyl dit negatief vir miristoliensuur (tabel 5) is. KV2 kontrasteer duidelik die somerwaardes van Durban (sD), Pretoria (sP) en Kaapstad (sK) as een groep met die somerwaardes van Bloem- fontein (sB) en Port Elizabeth (sPE) met al die winterwaardes as ' $n$ tweede groep. Dit is belangrik om daarop te let dat in die geval van UHTM, ongeveer $65 \%$ van die variasie tussen die drie groepe wat bespreek is deur $\mathrm{KV} I$ verteenwoordig word.

\section{BESPREKING}

Die doel van die studic was om die invloed van streke en seisoenale faktore op die samestelling van melk te ondersoek deur van meerveranderlike analise gebruik te maak. Dic KVAtegnick wat gebruik is, was geskik vir dié doel en het duidelik die verskillende groepe aangedui en ook getoon dat die omgewingstoestand wat die grootste invloed op die samestelling van melk wat ondersock is, gehad hel, die seisoenale verandering is. Die seisoenale invloed wat deur KV I verteenwoordig is, was vir die meeste variasie tussen die groepe verantwoordelik met waardes vall $37,6 \%$ vir VRM, $29.1 \%$ vir LVM en 64,9\% vir UIITM (label 2). Die melksamestellingskomponente met dic meeste diskriminasie tussen die groepe was vitamien $B_{2}$ vir VRM en LVM, terwyl dit velsure en cholesterol vir UHTM was.

\section{Minerale}

Die mineraalkonsentrasic van melk word nie maklik deur voeding of seisoene beïnvloed nie. Tydens dic statistiese verwerking van die data het kalsium (Ca) en fosfor (P), die twee

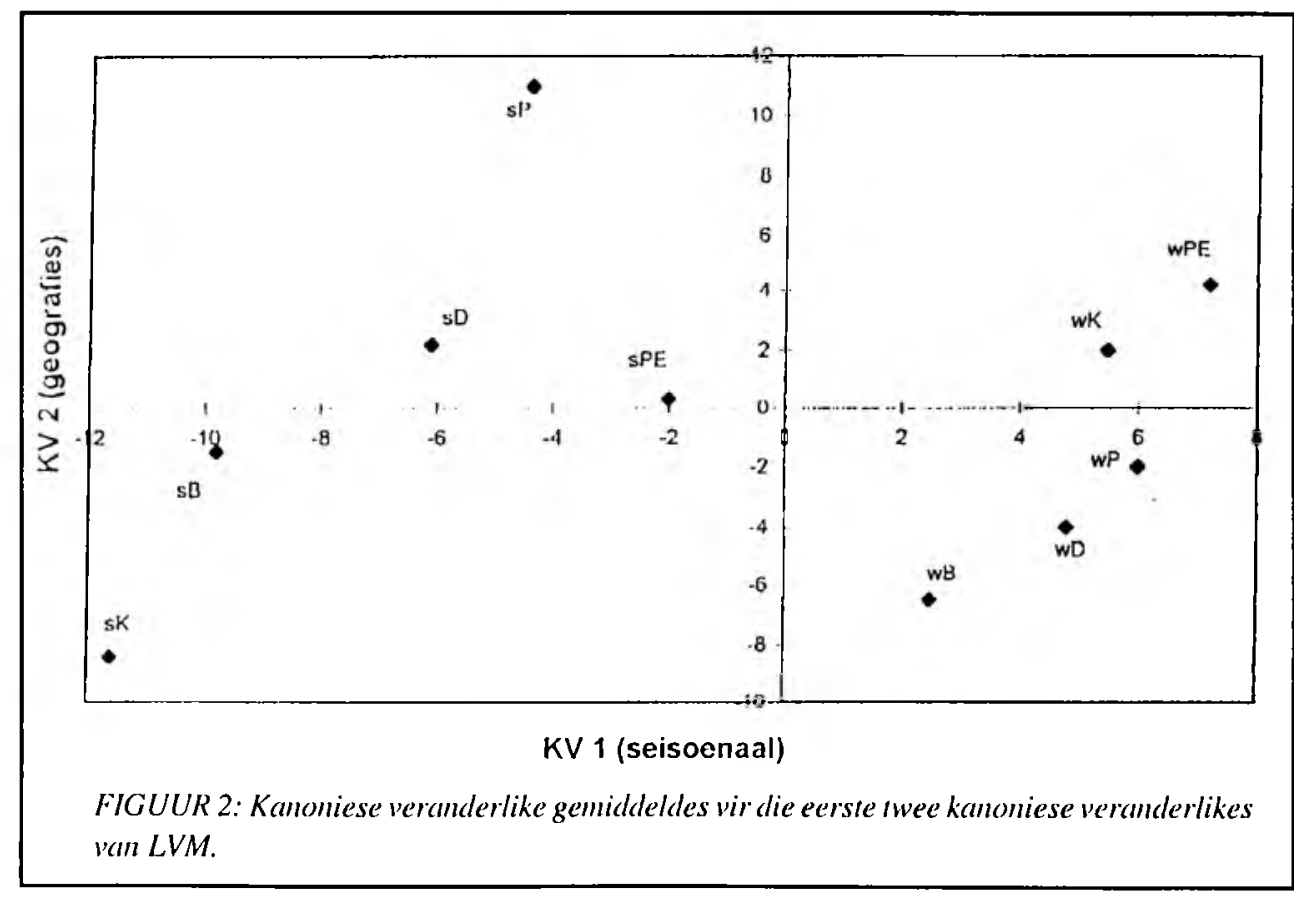

\begin{tabular}{|c|c|c|c|c|}
\hline \multicolumn{5}{|c|}{ KV1 } \\
\hline & & Groep 1 & Groep 2 & Groep 3 \\
\hline \multirow{2}{*}{$\begin{array}{c}\text { Melk- } \\
\text { komponent }\end{array}$} & \multirow[t]{2}{*}{$r$} & Somergemiddeld & Somergemiddeld & \multirow{2}{*}{$\begin{array}{c}\text { Wintergemiddeld } \\
\text { vir alle stede }\end{array}$} \\
\hline & & sB en sPE & sK, sP en sD & \\
\hline C14:1 & $-0,66$ & 9,84 & 7,42 & 7,28 \\
\hline C16:0 & 0,91 & 180,5 & 230,5 & 255,0 \\
\hline$C_{18: 1}$ & 0,92 & 181,2 & 235,9 & 272,2 \\
\hline cholesterol & 0,76 & 7,02 & 8,75 & 7,28 \\
\hline
\end{tabular}


belangrikste minerale in melk, nooit gediskrimineer nie, wat beteken dat hul konsentrasies nie noemenswaardig deur streke of seisoene beinvloed is nic. Ilicrdie eienskap is verblydend omdat hierdie twee minerale nic net belangrik is vir die vorming van gesonde bene en tande by kinders en die teenwerking van osteoperose by bejaardes nie, maar ook ' $n$ belangrike biologiese rol in verskeic metaboliese prosesse speel. ${ }^{1.4}$

Daar word gerapporteer dat melk mel 'n Ca:P-verhouding van 1,25-1,5:1 baic gunstig is vir Ca- $\mathrm{cn} P$ - opname by veral suigelinge en kinders. ${ }^{1,2}$ Tydens hierdie studie het dit aan die lig gekom (tabel 1) dat melk regoor die RSA gedurende die somer en winter wel aan die vereiste voldoen. Die volgende verhoudingswalardes is verkry: VRM (somer en winter) is $1,33: 1 ;$ LVM (somer) is 1,34:1 terwyl dit 1,39:1 vir die winter is en die waarde vir UHTM 1,30:1 in dic somer en 1,4:1 in die winter is.

Dic variasic in dic konsentrasic van natrium en kalium (by LVM) kan moontlik toegeskryf word aan verskillende wasmiddels wat gebruik word.'

\section{Vitamiene}

Vitamien $B_{1}$ (tiamien) diskrimineer in die somer as gevolg van die groot verskil tussen die somerwaardes valn Pretoria $(30,89$ $\left.\mu \mathrm{g} \cdot \mathrm{ml}^{-1}\right)$ en Kaapstad $\left(18,86 \mu \mathrm{g} \cdot \mathrm{ml}^{-1}\right)$. 'n Moontlike rede hicrvoor is dat vitamiene soos tiamien, maar ook piridoksien, kobalamien, foliensuur en askorbiensuur hittesensitief is en moontlik tydens die melkprosessering verlore kon gaan, ${ }^{5,6}$ Tiamienverliese is al by die volgende prosesse gerapportecr: ${ }^{5,6}$

$\begin{array}{lll}\text { Pastcurisering } & : 71-74{ }^{~ "} \mathrm{C} \text { vir } 40 \text { sck. } & :<10 \% \\ \text { UHT-behandeling } & : 135-150^{\circ} \mathrm{C} \text { vir } 1-5 \text { sck. } & : 0-20 \% \\ \text { Kook } & : 100)^{\circ} \mathrm{C} & : 10-20 \% \\ \text { Sterilisering } & : 110-120{ }^{\circ} \mathrm{C} \text { vir } 10-30 \mathrm{~min} . & : 20-50 \%\end{array}$

Bloemfontein-melk se tiamienwaardes is dic laagste in die land vir beide die somer-en wintermaande, terwyl dic grootste variasic tussen Pretoria en Kaapstad (tabel 4) voorkom. Die groot verskille kan moontlik toegeskryl word aan verskillende melkprosesseringstegnicke wat gebruik word.

Hierteenoor is die vetoplosbare vitamiene (A, D en E) asook die $B$-kompleksvitamiene ( $B_{2}$ of ribollavien, biotien, nikotiensuur, ens.) relatief stabiel en onsensitief vir hitte en kan die variasie van dic vitamicn $B_{2}$ waardes nic aan prosessering tocgeskryf word nic. Indien dic melk egter gesteriliseer word, mag daar van dic Bvitamiene verlore gaan. ${ }^{7.8}$

\section{Vetsure}

Dic leit dat melkvet genoeg kort-en mediumlengtevetsure bevat, verseker dat melkvet beter vertecrbaar is as enige ander vette in dic normale diect. Dic oksiedasictempo van vetsure is in die algemeen groter by vetsure met kort koolstofkettings." Omdat melkvet maklik verteer en maklik geabsorbeer word, plaas dit relatief min spanning op die liggaam en word dil as 'n waardevolle diectbestanddecl vir pasiënte met maag-, lewer-, galblaas- en nierprobleme beskou. . $\left(11.12^{2}\right.$

Melkvet bestaan uit 200 verskillende vetsure waarvan slegs 20 in verhoudings van meer as $1 \%$ voorkom. Slegs 11 daarvan is in hierdie studic bepalal. Dic 200 vetsure sluit versadigde, onversadigde en vertakle vetsure en sikliese verbindings in. ${ }^{11,13}$

Tydens die KVA-analise hel die volgende drie vetsure gediskrimineer (tabel 5): miristoliensuur (C14:1), palmitiensuur (C16:0) en oleïensuur (C18:1). Groot verskille lydens die someren wintermaande bestaan tussen die vetsure van melk vanal Bloemfontein en Durban. Die walardes vir miristoliensuur, palmitiensuur cn oleïensuur ( in mg. $100 \mathrm{ml}^{-1}$ ) is onderskeidelik 17,612 cn 654 vir Durban en 25,874 en 806 vir Blocmfontein.

Dit is bekend dat die vetsuursamestelling tydens die laklasieproses verander deurdat dic fraksie kortkeltingvetsure vinnig alneem en dit die mediumlengtevetsure tydens dic laaste twee derdes van die proses verminder. Die verhouding van steariensuur (C18), oleïensuur (C18:1) en linolcensuur (C1 8:2) verander voortdurend tydens die proses. ${ }^{14,15,16} \mathrm{Die}$ verskil tussen die oleiensuurkonsentrasie gedurende die somermaande tussen Groep I en Groep 2 van tabel 5, is moonllik as gevolg van melk wat in verskillende stadiums van die laktasieproses is.

'n Beter verklaring is dalk dat die gehalte van weiding dic fraksies louriensuur ( $\mathrm{Cl} 2$ ), miritiensuur ( $\mathrm{Cl} 4)$ cn palmiliensuur (Cl6) in die melkvet beïnvloed deur dit byvoorbecld te laat alneem. Indien dit dic geval is, sal clic hoeveclheid steariensuur en oleïensuur in die melkvel loenecm. Daar bestaan 'n positiewe korrelasic tussen dic hoeveclheid onversadigde vetsure in dic vet wat in voeding voorkom en dié wat in die melk voorkom. Die hoeveclheid poli-onversadigde vetsure in melkvet word noemenswaardig verminder deur hidrogenasie van die rumenbakterice. ${ }^{17.18}$

Wanneer kuilvoerrantsoene wat byvoorbecld klapperolic, sojaboonolic, lynolic of katoensaadolie beval gedurende dic wintermaande aln die kocie gevoer word, verhoog dic verhouding onversadigde vetsure in die melk. Deur byvoorbeeld wildesalfraanolie met die kuilvoer te vermeng, kan die konsentrasic onversadigde vetsure verdubbel word, terwyl die hocveclheid palmitoolsuur (Cl6:1) ook geweldig sal toeneem ten spyte daarvan dat hicrdic suur glad nie in wildesafframolic voorkom nic. ${ }^{1,19.20}$

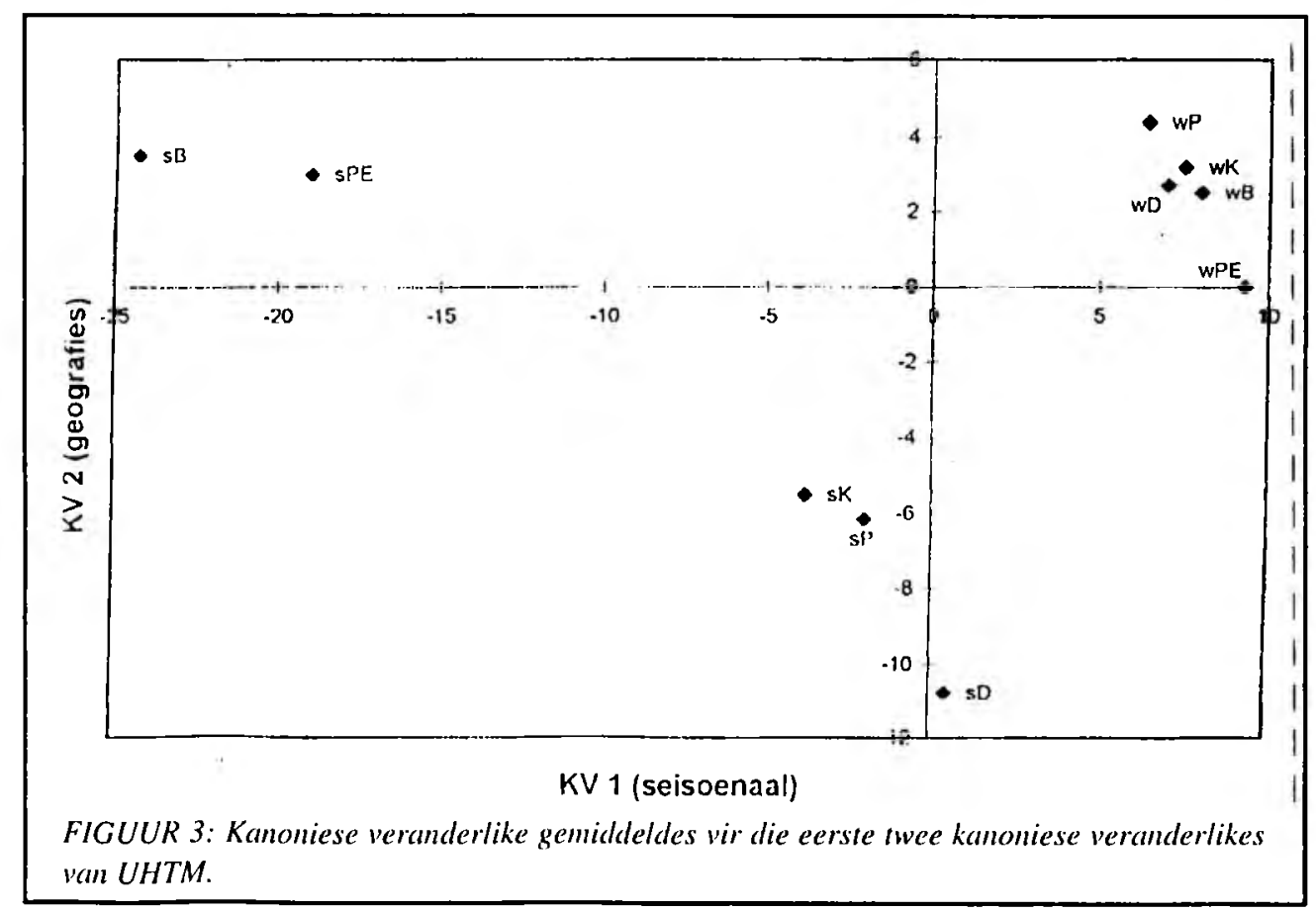


Die konsentrasie poli-onversadigde velsure in melk kan noemenswaardig verhoog word deur onversadigde olies (byvoorbeeld wildesalliranolie, sojaboonolic ol sonneblomolic), geënkapsuleer in kaseïen en met formaldehied verhard, by slic voer te voeg. Omdat sodanige kalseien bestand is teen rumenakliwiteite word die poli-onversadigde vetsure teen hidrogenering beskerm. Dic kaseien word dan ecrs later, in dic abomasumgedeclte van die spysverteringskanaal, gehidroliseer sodal die vetsure in die dunderm geabsorbeer word. Op die manier kan die verhouding poli-onversadigde vette, veral linoleiensuur (C18:2) tussen 20-36\% verhoog word. Terselrdertyd word die lraksies miritiensuur, palmitiensuur, stearriensuur en oleïensuur verlang. ${ }^{22,23,24}$

Dit is dus duidelik dat dic laktasieproses en die voer of weiding wat die beeste vreel die grootste invloed op die samestelling valn die konsentrasies vetsure in melk hel. Omdatt die tipe voer wat gedurende die somer- en wintermaande gevreet word baic verskil, is daar ook gedurende hierdie seisoene duidelike verskille in dic samestelling van dic melkvet. Die watardes in tabel 6 wall met die RSA-waardes van die verskillende stede vergelyk word, is uit verskeic internasionale publikasies versamel en verteenwoordig die gemiddelde watardes vir die belangrikste vetsure in melkvet tydens die somer- en winter- maiande. 1,25

Volgens label 6 verskil die RSA-walardes vir oleiensuur slegs $0,5 \%$ lydens winter- en somermatande, terwyl die internasionale waardes' $n$ noemenswalardige $7,3 \%$ verskil toon. Dieselfde geld vir linolecnsuur waar die internasionale walardes verdubbel in die somer terwyl die RSA-waarde effens afneem.

\section{Cholesterol}

In UIITM was cholesterol een van die diskriminerende melkkomponente. Cholesterol verteenwoordig die grootste gedeclte van die sterole in melkvet en in die meeste dicelvette van dierlike oorsprong. Sommige navorsers glo dal 'n hoë konsentrasic cholesterol in die dieet die cholesterolvlak in die bloedserum verhoog, wat weer die risiko van koronêre hartsiektes en arteriosk lerose of aarverkalking verhoog. Op grond hiervan word die aamname gemaak dat die verbruik van dierevet en ook die van melk vet verminder moet word om sodoende die cholesterolinname in die diect te verminder. ${ }^{2 x}$. $\left.x\right)$ Ilierdie stelling het nie slegs die verbruik van melk verminder nie, malar ook baie mense van goeie gesondheid berool. ${ }^{2 k .2 y}$

Tydens hierdie studie is bevind dat die vlak van cholesterol $\left(8,9 \mathrm{mg} .100 \mathrm{~g}^{-1}\right)$ in Suid-A rikalanse melk, landswyd, lydens dic

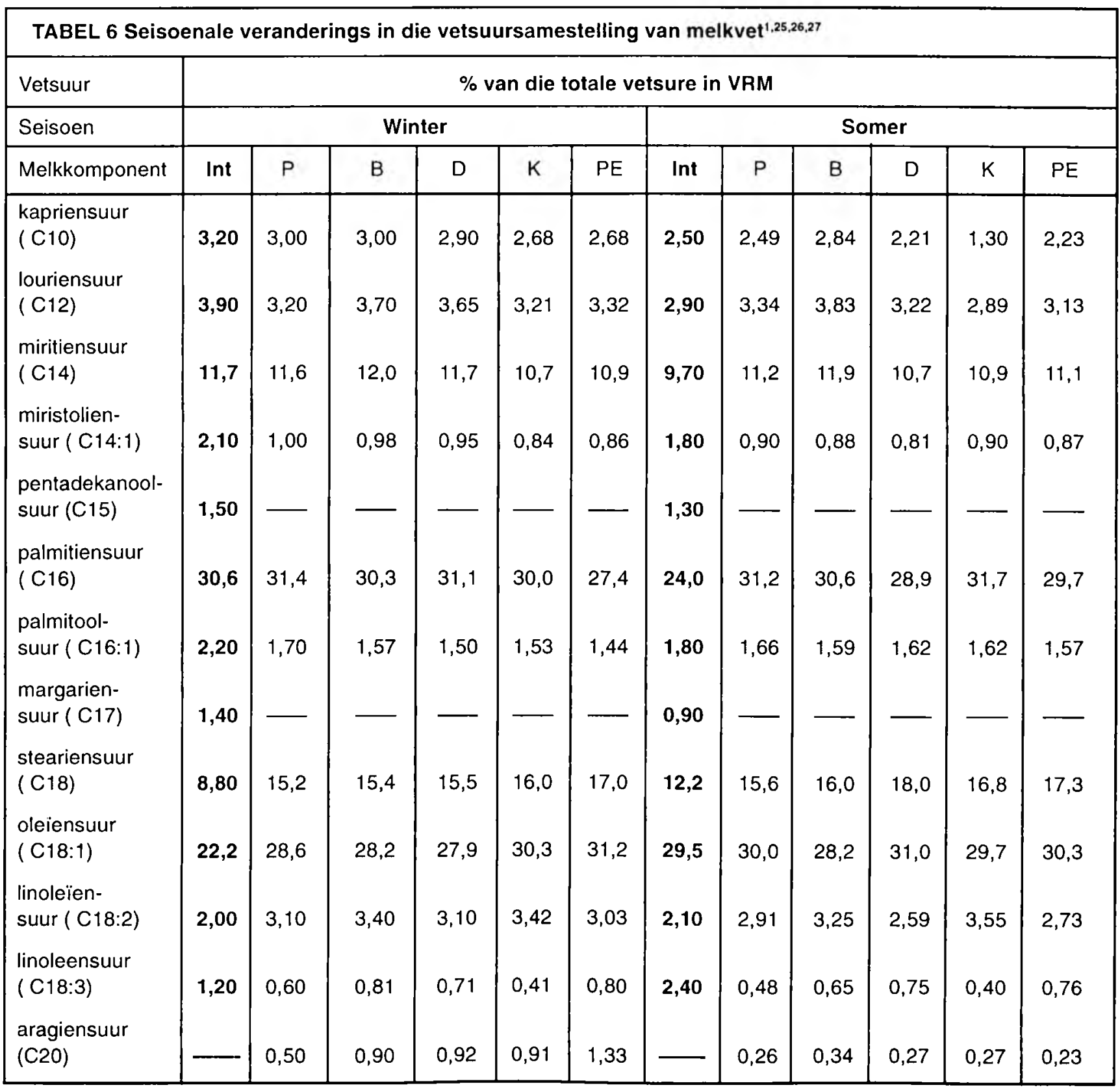


somer- en wintermaande laer is as die internasionale waardes (13 mg. $\left.100 \mathrm{~g}^{-1}\right)$. Ongeveer $80 \%$ van die cholesterol wat in melk aangetref word, is in die vry of ongebonde toestand terwyl slegs 'n klein hoeveelheid verester is.' Die hoogste cholestrolwaardes tydens hierdie studie is vanaf UHTM verkry wat tydens die winter in Blocmfontcin gekoop is $\left(13,39 \mathrm{mg} .100 \mathrm{~g}^{-1}\right)$, terwyl dic laagste waardes van LVM verkry is wat lydens die somer in Kaapstad $\left(4,05 \mathrm{mg} .100 \mathrm{~g}^{-1}\right)$ gekoop is.

Internasionale waardes van die gemiddelde cholesterolwaardes in verskillende kossoorte verskyn in label 7. Die gemiddelde SA-waardes vir VRM en LVM verskyn lussen hakies.

Dit is verder interessant om te weet dat die menslike liggaam self meer cholesterol vervaardig as wat deur dic dicet geabsorbeer kan word en dat cholesterol verskeic belangrike lunksies in die liggaam vervul. Cholesterol is byvoorbecld ' $n$ belangrike struklurele komponent van selmembrane, is die beginproduk vir die vervaardiging van steroiedhormone en vorm 'n belangrike deel van die senuweeweefsel., ${ }^{1,21}$

\section{Summary}

The aim of the study was to attain a better understanding of scasonal and regional factors which could contribute to variation in milk nutrients by means of multivariate analysis. Canonical variate analysis, also known as linear discriminant analysis, was used as statistical technique. This technique is normally used when it is of more interest to show differences among groups than among individuals. Canonical variate analysis indicated that of all environmental conditions the scasonal differences had the greatest effect on the nutrient values, for the inilk being studied (full cream milk, low fat milk and ultra high tcmperature milk), as these were always the contrast in the first canonical variate, which accounted for most of the variability among groups and was $37,6 \%$ for full cream milk, $29,1 \%$ for low lat milk and $64,9 \%$ for ultra high temperature milk. The most discriminating nutricnts for full cream and low fat milk were similar viz. vitamin $B_{2}$ and cholesterol while for the ultril high temperature milk the most discriminaling nutrients were fatty acids and cholesterol.

There is clear seasonal variation in the composition of milk fat because it is affected by the composition of the leed. Average values for the proportion of the major fatty acids (South African and international values) are shown in table 6 . The table shows that during the summer all C18-fatty acids, but particularly oleic acid, are found in greater concentrations in milk fat than in the winter period. The international values indicated small differences between the concentrations of linoleic acid during the summer and winter, but the linolenic acid content just about doubled in summer. The South African values of li- nolenic acid was much lower during summer than winter. The fraction of palmitic acid, on the other hand, was much reduced during the summer period. ${ }^{1.25,23.27}$

The discrimination of vitamin $\mathrm{B}_{2}$ between regions may be due to the different milk processing techniques that are used. It is known that the fat soluble vitamins A,D and $E$ and the vitamins of the $B$ complex, ribollavin, pantothenic acid, biotin and nicolinic acid, are relatively insensitive to heat and generally no losses of these vilamins oceur when milk is heated. Only when heating is prolonged or when milk is sterilized slight reductions in vitamin $\mathrm{A}, \mathrm{E}$ and $\mathrm{B}_{2}$ occur. ${ }^{2.23}$

Cholesterol was one of the discriminating milk components in ultra high temperature milk. Although the cholesterol content of milk is relatively low compared to that of other animal loods, as can be seen from table 7, this study proves that the average cholesterol value of South African full cream milk $\left(8,9 \mathrm{mg} .100 \mathrm{ml}^{-1}\right)$ is lower than the international average $\left(13,39 \mathrm{mg} .100 \mathrm{ml}^{-1}\right)$ during the winter and summer period..$^{1.30 .31}$

\section{ERKENNING}

Die outcurs bedank dic LNR-Dictevoeding en Produktc Instituut, Irene vir toestemming verleen om hierdie werk te mag publisecr. Dankic aan dic personeel van die Aldeling Chemic, Suiwelbedryfsentrum wat dic analises uitgevoer het.

\section{IITERATUURVERWYSINGS}

I. Renner, E. (1983). Milk and Dairy Products in Fluman Nutrition (Justus-Liebig- University Giessen. Federal Republic ol Germany).

2. Hansen, R.G., Wysc, B.W., Brown, G. (1978). Nutrient needs and their expression, Food Techmol., 32, (2), 44 - 53.

3. Digby, P.G.N., Kempton, R.A. (1987). Mulrirariate Analysis of Ecological Commumities (Chapman and Hall, Lid. London) p. $76-79$.

4. Holt, C. (1982). Inorganic conslituents of milk. In The colloidal phosphate of cow's milk, J. Dairy Res., 49, 29 - 38.

5. Ford. J.E., Porter, J.W.G., Thompson, S.Y., Toothill, J., EdwardsWebb, J. (1969). Effects of ultra high temperature (UHT) processing and of subsequent storage on the vitamin content of milk, $J$. Dairy Res., 36, $447-454$

6. Graham, D.M. (1974b). Alternation of nutritive value resulting from processing and fortification of milk and milk products, J. Dairy Sci., 57, 738- 74.5.

7. Button, II., Ford, J.E., Franklin, J.G., Porter, J.W.G. (1967), Elfects of repeated heat treatments on the levels of some vitamins of the B-complex in milk, J. Dairy Res., 34, 193 - 197.

8. Head, M.K., Hansen, A.P. (1979). Suability ol L-Ascorbic acid added to whey, chocolate and low fat milks, J. Dairy Sici, 62, 352 - 354.

9. Lembke, A. (1980). Zum feltgehalt der konsummilch aus ernahrungsphsiologischer sicht, Milc/twiss, 35, 727 - 729.

10. Coombs, G.W., Kaye, D.A., Parodi, P.W. (1965). Preliminaty observations on the possible advantages of butterlat in coooking, N.Z.

TABEL 7. Gemiddelde cholesterolinhoud van verskillende kossoorte ${ }^{1,30,31}$

\begin{tabular}{|l|c|c|c|}
\hline Kossoort & $\begin{array}{c}\text { Cholesterolinhoud } \\
\text { (mg.100g-'-porsies) }\end{array}$ & Kossoort & $\begin{array}{c}\text { Cholesterolinhoud } \\
\text { (mg.100g'-porsies) }\end{array}$ \\
\hline volroommelk & $13(9,63)$ & wildsvleis & 110 \\
laevetmelk & $2(7,22)$ & garnale / mossels & 150 \\
moedersmelk & 20 & lewer & 280 \\
vis & $30-70$ & niertjies & 350 \\
vleis & $70-90$ & eier & 500 \\
\hline
\end{tabular}


J. Science, $8,144-148$.

11. Harper, W.J. (1981). Advances in chemistry of milk, J. Dairy Sci., 64. $1028-1037$.

12. Jensen, R.G., Ouinn, J.G., Carpenter, D.L., Sampugna, J. (1967) Gas licutid chromatographic amalysis of milk fatty acids: A review, J. Dairy Sci. 50, $119-126$.

13. Foissy, H. (1969). Erkenntnisse über zusammenhä̈nge zwischen Herz/Crieslaufertantungen und dem Verzehr von Milch, insbesondere von milchfett. Osterr, Milchwirtsch., 24, $406-409$.

14. Parodi, P.W. (1974). Variation in the fatty acid composition of milkfat: Effect of stage of lactation. Aust. J. Dairy Techmol., 29, $145-148$.

15. Senft, B., Klobasa, F. (1970a). Untersuchungen über das Fettsäurespektrum in der kolostralmilch von kühe. Milchwiss., 25, $391-394$.

16. Senft, B., Klobasa, F. (1970b). Untersuchungen über das Fettsî̈urespektrum in milchfett schwarzbunter kuihc. Milchwiss., 25 , $510-514$.

17. Stull, J.W., Brown, W.H., Waldez, C., Tucker, H. (1966). Fally acid composition of milk. III Variation with stage of lactation, J. Dairy Sci., 49, $1401-1405$.

18. Banks, W., Clapperton, J.L., Ferrie, M.E. (1976b). Effects of feeding fat 10 dairy cows recieving a fat-delicient basal diet. If Fally acid composition of the milk, J. Dairy Res., 43, $219-227$.

19. Meyer, F., Senft,B., Klobasa, A. (1976). Untersuchungen über das Fetsăuremuster des milchfettes im Hauptgemelk und in der Komplementärmilch, Milchıviss., 31, 419 - 421.

20. Hagemeister, H., Kaufmann, W. (1969). Das Fettsäuremuster des milchfettes bei Zufütterung von stearinsäure. Milchwiss., 24, 654 657.
21. Kiermeier, F., Wessinger, L., Renner, E. (1965). Beziehungen zwischen Futlergualitat und bestandteilen der milch, Milchwiss. 20, $404-408$

22. Buchanan, R.A., Rodgers, W.P. (1973) Manulacture of butter high in linolcic acid, Aust. J. Dairy Techlmol. 28, 175 - 178.

23. Cook, L.J., Scoll, T.W., P'an, Y.S. (1972) Formaldehyde-l1euledcasein-sunllower oil supplement for dairy cows. II Effect on the filly acid composition of plasma and milk lipids, J. Dairy Res., 39, $211-218$.

24. Czulack, J., Hammond, L.A., Horwood, J.F. (1974). Cheese and cultured dairy products from milk with high linoleic acid content, Atust. J. Dairy Technol., 29, $124-128$

25. Strocchi, A., Capella, P., Pallotta, U., Taddia, M. (1967). Industrie Agr, 5, 481-491.

26. Hall, A.J. (1970). Seasonal and regional variations in the fally acid composition of milkfat, Dairy Industr. 35, $20-24$.

27. Hution, K., Secly, R.C., Armstrong, D.G. (1969). The variation throughout a year in the fatty acid composition of milk fat from two dairy heards, J. Dairy Res., 36, 103 - 113.

28. Homer, D.R., Virtanen, A.I. (1967) Cow's milk cholesterol - Studies on the milk of cows on normal and protein-fice feeds, Milchwiss. 22.

29. Parodi, P.W. (1973) The sterol content of milktat, animal fats, malgarines and vegetable oils, Aust. J. Techol, 28,135 - 137.

30. Phillips, M.C., Briggs, G.M. (1975) Symposium: Milk and Dairy Products for the American diet. Milk and its role in the American dict, J. Dairy Sci., 58, 175I - 1763.

31. Rusoff, L.L. (1970) Milk: Its nutritional value at a low cost for people of all ages, J. Dairy Sci., 53, $1296-1302$. 